\title{
UMA PROPOSTA DE ENSINO-APRENDIZAGEM DE INGLÊS PARA FINS ESPECÍFICOS BASEADA NO ENSINO HÍBRIDO
}

\author{
UNA PROPUESTA DE ENSEÑANZA Y APRENDIZAJE DE INGLÉS CON FINES \\ ESPECÍFICOS BASADA EN LA ENSEÑANZA HÍBRIDA
}

\author{
A TEACHING-LEARNING PROPOSAL OF ENGLISH FOR SPECIFIC PURPOSES \\ BASED ON BLENDED TEACHING
}

\author{
Yna Honda de SOUSA ${ }^{1}$ \\ Andréa Pereira MENDONÇA ${ }^{2}$ \\ Iandra Maria Weirich da Silva COELHO ${ }^{3}$
}

RESUMO: Neste artigo, apresentamos uma proposta de ensino-aprendizagem de Inglês para Fins Específicos, denominada Blended English Teaching (BET), que combina ensino híbrido, recursos virtuais para estudo autônomo e um corpus compilado com textos autênticos, referentes a manuais e tutoriais de hardwares e softwares. O objetivo desta proposta é contribuir para a proficiência na habilidade de leitura em inglês dos alunos no que diz respeito à decodificação de palavras e integração de ideias. Os resultados indicaram que a proposta BET contribuiu de maneira mais significativa para a proficiência na habilidade de leitura em inglês, no critério decodificação de palavras, não sendo igualmente efetiva no critério integração de ideias. Como resultado deste trabalho, desenvolvemos um Guia Didático para Professores contendo orientações e materiais de suporte que permitem a reprodução de BET em outros contextos de ensino.

PALAVRAS-CHAVE: Inglês para fins específicos. Ensino híbrido. Recursos virtuais. Corpus.

RESUMEN: En este artículo, presentamos una propuesta de enseñanza y aprendizaje de Inglés con Fines Específicos, denominada Blended English Teaching (BET), que combina enseñanza híbrida, recursos virtuales para el estudio autónomo y un corpus compilado con textos auténticos, con relación a manuales y tutoriales de hardwares y softwares. El objetivo de esta propuesta es contribuir al desarrollo de las habilidades de lectura en inglés de los alumnos en lo que se refiere a la decodificación de palabras e integración de ideas. Los resultados indicaron que la propuesta BET contribuyó de manera más significativa en la habilidad de comprensión de lectura en inglés, en el criterio decodificación de palabras y no fue igualmente efectiva para el criterio de integración de ideas. Con el resultado de este trabajo,

\footnotetext{
${ }^{1}$ Instituto Federal de Educação, Ciência e Tecnologia do Amazonas (IFAM), Manaus - AM - Brasil. Mestre em Ensino Tecnológico. Professora de Língua Inglesa. ORCID: <http://orcid.org/0000-0001-8601-7783>. E-mail: ynahonda@gmail.com

${ }^{2}$ Instituto Federal de Educação, Ciência e Tecnologia do Amazonas (IFAM), Manaus - AM - Brasil. Doutora em Ciência da Computação. Professora de Processo e Desenvolvimento de Software. ORCID: <http://orcid.org/00000003-4251-5312>. E-mail: andrea.ifam@gmail.com

${ }^{3}$ Instituto Federal de Educação, Ciência e Tecnologia do Amazonas (IFAM), Manaus - AM - Brasil. Doutora em Linguística. Professora de Língua Espanhola. ORCID: 〈http://orcid.org/0000-0003-3513-962X〉. E-mail: iandrawcoelho@gmail.com
} 
desarrollamos una Guía Didáctica con orientaciones y materiales para los docentes que permite la reproducción de BET en otros contextos de enseñanza.

PALABRAS CLAVE: Inglés con fines específicos. Enseñanza híbrida. Recursos virtuales. Corpus.

ABSTRACT: In this article, we present a teaching-learning proposal of English for Specific Purposes, called Blended English Teaching (BET), which combines blended teaching, virtual resources for self-study and a compiled corpus with text authorship, manual reference about hardwares and softwares. The purpose of this proposal is to contribute to the English language reading skill to students with regard on decoding of words and integration of ideas. The results of BET research contributed to a greater proficiency in reading texts, with the aim of contributing to the improvement of the integration of ideas. With this work, we have developed a Teaching Guide for Teachers and support materials that allow the reproduction of BET in other teaching contexts.

KEYWORDS: English for specific purposes. Blended teaching. Virtual resources. Corpus.

\section{Introdução}

De modo geral, o currículo dos Cursos Técnicos dispõe de uma disciplina, denominada de Inglês Instrumental ou Inglês para Fins Específicos (doravante IFE), cuja dinâmica de ensino consiste, frequentemente, em aplicar técnicas de leitura com base em textos da área de conhecimento dos alunos, a fim de desenvolver habilidades de leitura e compreensão de textos em inglês.

O desenvolvimento da habilidade de leitura requer dos alunos a mobilização de vários conhecimentos, tais como a decodificação de palavras, integração de ideias, realização de inferências e sumarização (GONÇALVES, 2008; TUMOLO; TOMITCH, 2007). Destes, os primeiros (decodificação e integração) são fundamentais para a progressão dos alunos, pois permitem que eles reconheçam as palavras que lêem e as compreendam, favorecendo o conhecimento do vocabulário específico da área (decodificação de palavras) e, também, propiciem uma representação coerente das ideias presentes no texto, quando o leitor estabelece relações entre as proposições, sem que seja preciso fazer uma tradução literal do mesmo (integração de ideias) (BRAUER, 2014; TUMOLO; TOMITCH, 2007).

Dada à importância dos aspectos mencionados para a habilidade de leitura, desenvolvemos uma proposta de ensino-aprendizagem denominada Blended English Teaching (doravante BET), em que acrescentamos outros elementos, além da aplicação das técnicas que são comumente adotadas, são eles: (i) os modelos de ensino híbrido, Sala de aula Invertida 
(SAI) e Rotação por Estações de Trabalho (RE) para reorganizar o espaço de sala de aula; (ii) recursos virtuais para auxiliar no estudo autônomo (plataforma adaptativa Duolingo, videoaulas de canais de ensino do YouTube, sites e dicionário digital); e, (iii) um corpus compilado com textos em inglês que serviu como base para a preparação de atividades de aprendizagem, proporcionando contato do estudante com o léxico da área mais frequente.

Para avaliar esta proposta, aplicamos BET com alunos do Curso Técnico de Nível Médio em Informática de uma Instituição Federal de Ensino no primeiro semestre acadêmico de 2017. Os resultados revelaram que BET foi mais efetiva para o desenvolvimento da habilidade de decodificação de palavras, evidenciando também alguns cuidados que professores de disciplinas de IFE devem ter no ensino de cognatos, falsos cognatos e, principalmente, na elaboração de frases em português para representação de seu entendimento do texto ou fragmento do texto em inglês. Este aspecto da escrita precisa ser observado com atenção, levando em conta o fato de que é por meio da escrita que alunos são frequentemente, avaliados em testes profissionais para vagas de emprego ou testes de proficiência.

Os detalhes de BET, os procedimentos metodológicos investidos em sua avaliação, assim como o detalhamento dos resultados são apresentados nas próximas seções.

\section{Os Fundamentos de BET (Blended English Teaching)}

Blended English Teaching (BET) é uma proposta de ensino-aprendizagem de IFE, idealizada para aprimorar a habilidade de leitura em inglês, focando na decodificação de palavras e integração de ideias, que está fundamentada na tríade: modelos de ensino híbrido (SAI e RE); recursos virtuais para proporcionar o estudo autônomo dos alunos em sala de aula e extraclasse; e um corpus compilado com textos oriundos de manuais e tutoriais em inglês, relacionados a hardwares e softwares, que nortearam a elaboração das atividades de aprendizagem realizadas em sala de aula.

\section{Ensino híbrido}

Ensino híbrido, também chamado Blended Teaching, é um modelo que combina ensino on-line e off-line (SOUZA; ANDRADE, 2015). O off-line é caracterizado pela organização da sala de aula, com os alunos aprendendo em pequenos grupos ou com toda a turma, com o 
acompanhamento do professor ou em determinadas situações de forma individual. No estudo on-line, por sua vez, o aluno utiliza recursos virtuais (vídeos, acesso a sites, aplicativos e plataformas digitais, por exemplo) para acessar o material didático e estudá-lo de forma autônoma.

Há várias formas de implementar ensino híbrido (CHRISTENSEN; HORN; STAKER; 2013), no caso de BET utilizamos uma combinação dos modelos de Sala de Aula Invertida (SAI) e Rotação por Estações (RE). No modelo de sala de aula invertida, o ensino é organizado de tal modo que os alunos estudam o conteúdo (ou parte dele) fora de sala de aula e, em sala, dedicam o tempo para tirar dúvidas e pôr em prática o conteúdo.

No modelo de rotação por estação, a sala de aula é organizada em estações de trabalho com propósitos específicos que contribuem para o objetivo principal da aula. Neste modelo, os alunos devem rotacionar por todas as estações, a fim de alcançar os objetivos pretendidos para a aprendizagem.

\section{Recursos virtuais}

A adoção de modelos de ensino hibrido pressupõe a adoção de recursos virtuais que possibilitem ao estudante aprender o conteúdo de forma on-line (BERGMANN; SAMS, 2016). Para a implementação de BET foram previamente estabelecidos um conjunto de recursos virtuais, tais como: videoaulas oriundas de canais ${ }^{4}$ de ensino de Inglês no YouTube, dicionários digitais $^{5}$ (disponibilizados para download na Internet), sites da Internet para consulta e a plataforma adaptativa ${ }^{6}$ Duolingo.

Duolingo é uma plataforma para aprendizagem de idiomas (inglês, espanhol, francês, entre outros), $100 \%$ gratuita, gamificada, lançada em 2011. Dispõe de um conjunto de conteúdos organizados em lições, que são agrupadas por níveis de conhecimento (DUARTE,

\footnotetext{
${ }^{4}$ Neste estudo, utilizamos 20 canais de ensino selecionados do YouTube que apresentam videoaulas para auxiliar nas aulas de inglês, são eles: Manual do Inglês, Textelling Activities, UNIVESP, Inglês Winner, Eduardo Gafa, Carina Fragozo, Instantâneo Aulas, Bom de Língua, Verbo ENEM, Educação Ativa Idiomas, Babbel Português, Spark English, Nossa Língua, GetUsp, What'sUp?, Escola Online, Inglês no Teclado, Kevin Porter, Mr. Teacher Paulo, Teacher Allie.

${ }^{5} \mathrm{Na}$ proposta BET, optamos por utilizar o dicionário digital "Dicionário de Informática e Internet”, de Márcia Regina Sawaya (1999), em formato pdf e disponível para acesso on-line. Neste dicionário digital, os alunos têm acesso a variados termos utilizados na área de Informática e também na Internet.

${ }^{6}$ De modo simples, podemos entender uma plataforma adaptativa como um sistema web, beneficiado de recursos de inteligência artificial e que, a partir de dados das atividades realizadas pelos alunos, seus percentuais de acertos e erros, recomenda o estudo de determinados conteúdos e a realização de determinadas atividades, respeitando o progresso individual de cada aluno (PORVIR, 2018).
} 
2014). A metodologia empregada na plataforma Duolingo contempla tarefas (exercícios de gramática, leitura, compreensão oral, conversação e vocabulário) e lições que englobam conteúdos gramaticais, tais como: substantivos, adjetivos, advérbios, verbos, preposições, pronomes, entre outros, divididas em unidades básicas, intermediárias e avançadas.

A plataforma pode ser utilizada para fornecer suporte e acompanhamento do conteúdo ministrado nas aulas presenciais e prática nas salas de aulas de inglês e, inclusive, os alunos podem utilizá-la em atividades extraclasse, de maneira autônoma, ampliando os estudos e práticas das habilidades comunicativas em inglês.

A plataforma disponibiliza recursos que permitem ao professor acompanhar o rendimento de cada estudante e monitorar quais conteúdos eles precisam refazer ou àqueles que foram aprendidos com a realização das tarefas. Este recurso ajuda a detectar pontos fortes e fracos acerca dos elementos gramaticais, suas funções e significados, bem como de vocabulário da língua.

\section{Corpus}

Um corpus pode ser entendido como um conjunto de dados linguísticos (pertencentes ao uso oral ou escrito da língua, ou a ambos), sistematizados segundo determinados critérios, suficientemente extensos em amplitude e profundidade, de maneira que sejam representativos da totalidade do uso linguístico ou de algum de seus âmbitos (BERBER SARDINHA, 2004, p. $18)$.

Para a implementação de BET compilamos um corpus de manuais e tutoriais referentes a hardwares e softwares, cuja organização atendeu a critérios fundamentados na Linguística de $\operatorname{Corpus}^{7}$ (BERBER SARDINHA, 2004): (i) coleta de textos autênticos; (ii) critérios rígidos de coleta do conteúdo; e (iii) finalidade. Tendo em vista a verificação da representatividade, o corpus compilado neste trabalho teve o total de 3.800.947 palavras, sendo classificado como Médio-Grande, conforme Berber Sardinha (2004, p. 26).

O corpus compilado serviu como referência para a elaboração das atividades de aprendizagem (gramática, vocabulário, leitura e compreensão de textos). A partir da compilação do corpus foi possível verificar as palavras mais frequentes da amostra para subsidiar a escolha

${ }^{7}$ A Linguística de Corpus “ocupa-se da coleta e exploração de um conjunto de dados linguísticos textuais coletados criteriosamente com o propósito de servirem para a pesquisa de uma língua ou variedade linguística” (BERBER SARDINHA, 2000, p. 325). 
de elementos gramaticais (cognatos, falsos cognatos, estrangeirismos, prefixos e sufixos, substantivos, adjetivos etc.) e com esta lista de palavras mais frequentes, foram elaboradas as atividades de ensino-aprendizagem visando à compreensão leitora em inglês.

\section{BET - Detalhamento}

Conforme falado anteriormente, BET (Blended English Teaching) é uma proposta de ensino-aprendizagem de Inglês para Fins Específicos, concebida para desenvolver a proficiência na habilidade da leitura em inglês, especificamente, no que diz respeito à decodificação de palavras e integração de ideias, tendo como público-alvo, alunos dos Cursos Técnicos de Informática.

BET combina os modelos de sala de aula invertida e rotações por estações de trabalho, conforme ilustrado na Figura 1. O modelo de Rotação por Estações (RE) é implementado em sala de aula (presencial), por meio da realização de três estações denominadas: Warm Up (aquecimento), Red (vermelho) e Blue (azul). Para cada estação é definido um tempo para a realização das atividades. Ao final deste tempo, os alunos devem realizar a rotação entre as estações.

Figura 1 - Organização da proposta de ensino-aprendizagem

\section{BET}

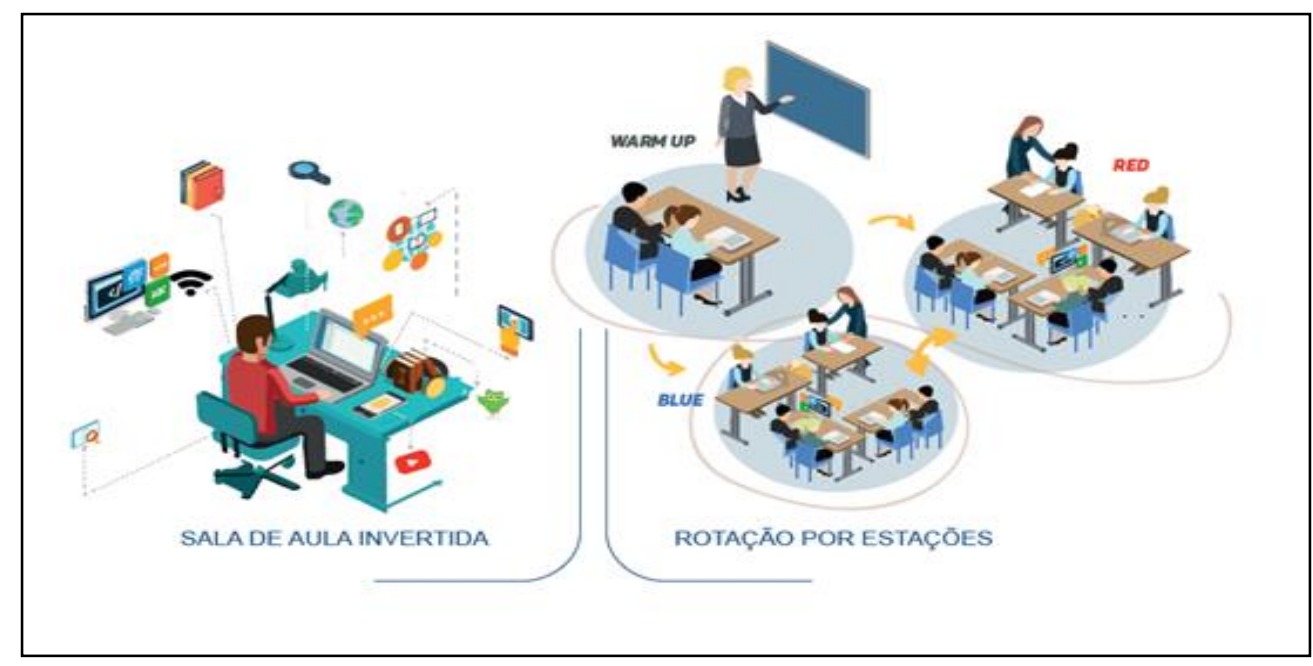

Fonte: Elaboração própria (2017)

Na estação Warm Up, todos os alunos participam das instruções com o professor acerca do conteúdo estabelecido para cada aula. A dinâmica nesta estação funciona como uma miniaula expositiva e dialogada, na qual há explicações rápidas sobre as técnicas de leitura e 
espaço para que eles tirem dúvidas sobre os conteúdos estudados fora de sala de aula (modelo SAI). Ao concluir as atividades na estação Warm Up, os alunos optam por qual estação desejam prosseguir com as atividades da aula e se direcionam para a estação Red ou Blue, onde ocorrem as atividades de aprendizagem.

Cada estação (Red e Blue) possui objetivos de aprendizagem a serem alcançados pelos alunos. Estes objetivos dizem respeito à habilidade de leitura quanto à decodificação de palavras e integração de ideias. Para atingir tais objetivos, os alunos desenvolvem exercícios que envolvem conhecimentos sobre vocabulário, gramática, bem como exercitam as técnicas de leitura, por meio das atividades que são propostas em cada estação.

Conforme mencionado anteriormente, cada estação possui um tempo pré-definido e ao final deste tempo, os alunos devem realizar a rotação nas estações, isto é, alunos que estavam na estação Red passam para a estação Blue e vice-versa. No caso de o aluno concluir as atividades da estação antecipadamente, solicita-se que este espere até a finalização do tempo para fazer a rotação.

Nas estações, os alunos realizam as atividades de aprendizagem individualmente, no entanto, têm acesso a dicionários, podem tirar dúvidas com o professor e interagir com outros colegas na estação. A prática de consultas e trocas de ideias fazem parte do ambiente profissional e, portanto, são preservadas na dinâmica destas estações.

No que diz respeito à implementação do modelo Sala de Aula Invertida (SAI), o professor provê, por e-mail, orientações e materiais didáticos para que os alunos estudem previamente e de forma autônoma os temas que serão abordados na aula seguinte, utilizandose recursos virtuais, tais como, YouTube e plataforma Duolingo.

No YouTube, os alunos têm acesso às videoaulas, as quais têm em média duração de 3 minutos e compreendem temas variados, tais como, dicas de técnicas de leitura e interpretação, cognatos, falsos cognatos, marcadores do discurso, entre outros. Por serem vídeos curtos, que permitem aos alunos assisti-los no seu tempo e ritmo, as videoaulas constituem um importante recurso didático, quando se recorre à sala de aula invertida (BERGMANN; SAMS, 2016).

Quanto à plataforma Duolingo, seu uso em BET é ilustrado na Figura 2. O professor, inicialmente, cria uma turma no Duolingo e seleciona tarefas a serem realizadas pelos alunos fora de sala de aula, comunicando-os por e-mail. As tarefas indicadas podem ser resolvidas pelos alunos, no tempo e local mais conveniente, e podem utilizar computadores, celulares ou outros dispositivos móveis. Por meio do aplicativo Duolingo para Escolas, o professor monitora o desempenho dos alunos nas tarefas e ainda recebe um relatório semanal sobre o andamento da turma. A partir deste relatório, o professor faz seus registros pessoais de 
acompanhamento da turma e encaminha feedback aos alunos, mantendo, assim, o incentivo ao estudo autônomo.

A adoção desta plataforma tem por finalidade motivar o contato com o idioma para além de sala de aula, prover mais acesso a conteúdo de suporte à língua inglesa e potencializar a aprendizagem do inglês, sobretudo, para aqueles alunos com pouco contato prévio com o idioma.

Figura 2 - Fluxo da dinâmica de utilização com a plataforma Duolingo

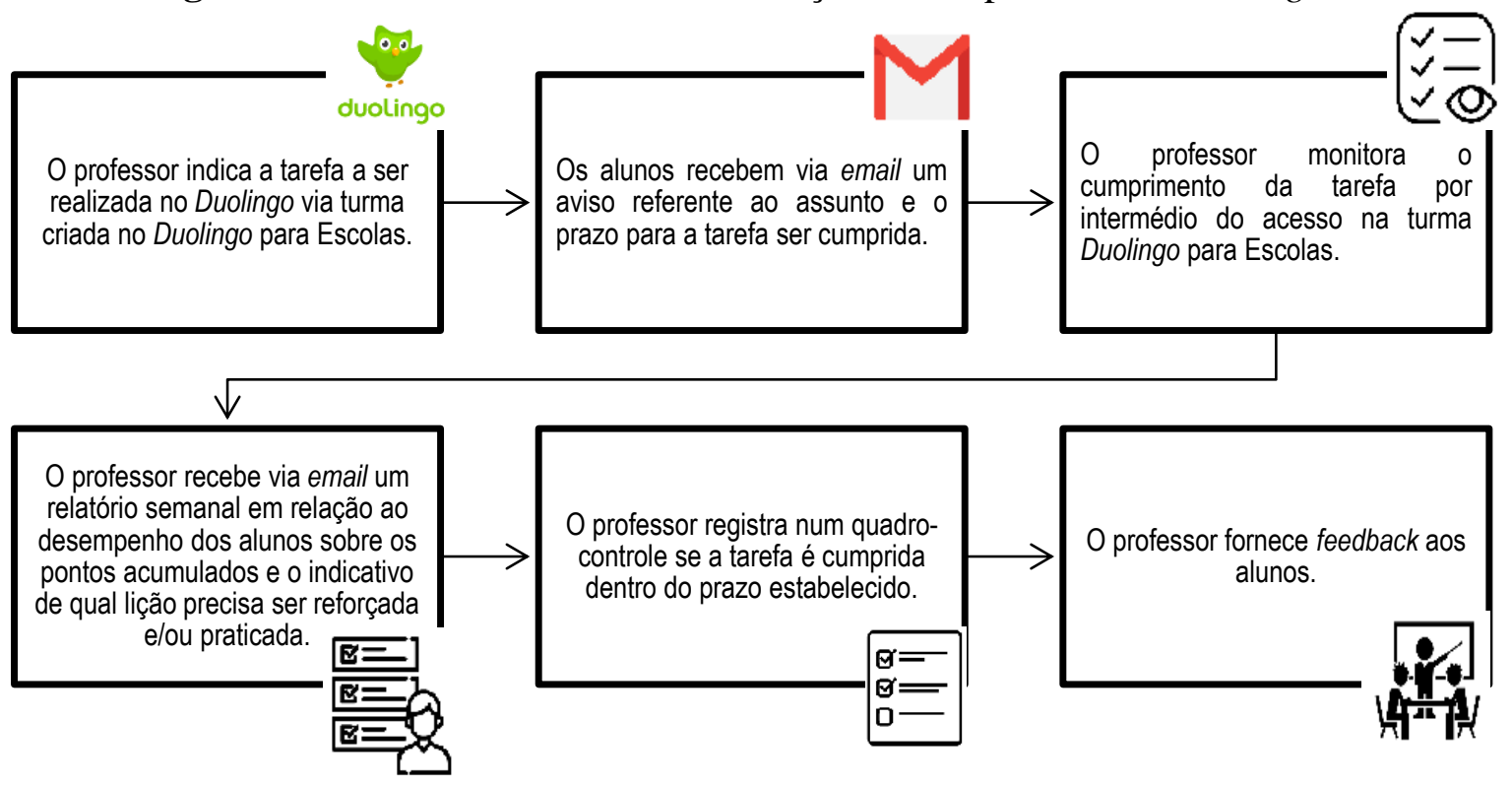

Fonte: Elaboração própria (2017)

Atualmente, há muitas plataformas disponíveis e o professor que desejar utilizar BET pode escolher outra de sua preferência ou até mesmo substituí-la por recursos virtuais que considerar mais pertinente. O importante é que os alunos possam ter acesso aos recursos virtuais apropriados que os permitam acesso aos materiais didáticos de suporte para o estudo autônomo.

\section{Avaliação de BET}

A fim de avaliarmos a efetividade desta proposta, aplicamos BET no primeiro semestre acadêmico de 2017, com 19 (dezenove) alunos, regularmente matriculados na disciplina Inglês Instrumental, com carga horária de 40h, pertencente à matriz curricular do Curso Técnico de Nível Médio Subsequente em Informática de uma Instituição Federal de Ensino.

No Quadro 1, apresentamos uma síntese das etapas e atividades desenvolvidas na implementação de BET. A etapa de procedimentos iniciais teve a finalidade de esclarecer a 
dinâmica das aulas e apresentar os recursos virtuais a serem utilizados pelos alunos. Procedemos também com um diagnóstico inicial que teve como objetivo identificar os conhecimentos prévios dos alunos, com relação à habilidade de leitura, decodificação de palavras e integração de ideias, considerando textos em inglês e para isso foi realizada uma avaliação individual.

Quadro 1 - Síntese da implementação da proposta de ensino-aprendizagem BET

\begin{tabular}{|c|c|c|c|}
\hline Etapas & Dias & Carga horária & Atividades desenvolvidas \\
\hline $\begin{array}{l}\text { Procedimentos } \\
\quad \text { iniciais }\end{array}$ & 1 & $2 \mathrm{~h}$ & $\begin{array}{l}\text { - Orientações sobre a dinâmica das aulas e } \\
\text { os recursos virtuais para estudo autônomo: } \\
\text { videoaulas, sites de consulta e materiais de } \\
\text { apoio (dicionário eletrônico); } \\
\text { - Criação do e-mail da turma; } \\
\text { - Cadastro e esclarecimentos sobre a } \\
\text { plataforma Duolingo; }\end{array}$ \\
\hline $\begin{array}{l}\text { Diagnóstico } \\
\text { Inicial }\end{array}$ & 1 & $1 \mathrm{~h} 30$ & Execução da avaliação inicial. \\
\hline Ambientação & 1 & $2 \mathrm{~h}$ & $\begin{array}{c}\text { Familiarização com a dinâmica das } \\
\text { estações. }\end{array}$ \\
\hline $\begin{array}{l}\text { Implementação } \\
\text { da proposta } \\
\text { BET } \\
\end{array}$ & 11 & $22 \mathrm{~h}$ & $\begin{array}{l}\text { Aulas em que foram realizadas as } \\
\text { atividades de ensino-aprendizagem, } \\
\text { considerando os modelos SAI e RE. }\end{array}$ \\
\hline Feedback & 4 & $8 \mathrm{~h}$ & $\begin{array}{c}\text { Feedback aos alunos referente às atividades } \\
\text { de aprendizagem corrigidas. }\end{array}$ \\
\hline $\begin{array}{l}\text { Diagnóstico } \\
\text { Intermediário }\end{array}$ & 1 & $1 \mathrm{~h} 30$ & Execução da avaliação intermediária. \\
\hline $\begin{array}{l}\text { Diagnóstico } \\
\text { Final } \\
\end{array}$ & & $1 \mathrm{~h} 30$ & Execução da avaliação final. \\
\hline $\begin{array}{l}\text { Questionário de } \\
\text { avaliação da } \\
\text { proposta BET }\end{array}$ & 1 & $30 \mathrm{~min}$ & $\begin{array}{l}\text { Aplicação do questionário de avaliação de } \\
\text { BET. }\end{array}$ \\
\hline
\end{tabular}

Fonte: Elaboração própria (2017)

Dado que era a primeira vez que os alunos estavam passando por uma experiência de ensino híbrido, desenvolvemos uma atividade de ambientação: no caso de SAI, orientamos os alunos para o uso da plataforma Duolingo e para a visualização das videoaulas. No caso de RE, familiarizamos os alunos com a dinâmica das estações Warm Up, Red e Blue, principalmente em relação ao tempo para realização das atividades (30 minutos para cada estação).

A implementação de BET propriamente dita foi realizada ao longo de 11 (onze) aulas de duas horas cada, havendo feedback contínuo ao longo das aulas. Este feedback era provido por meio de correção das tarefas, monitoramento do desempenho dos alunos nas atividades realizadas fora de sala de aula e esclarecimento de dúvidas.

Realizamos duas avaliações individuais com os alunos (diagnóstico intermediário e final). A primeira, realizada após a quinta $\left(5^{\mathrm{a}}\right)$ aula e a última, após a décima primeira $\left(11^{\mathrm{a}}\right)$ 
aula. O objetivo destas avaliações era identificar a proficiência na habilidade da leitura em inglês dos alunos, promovendo, em conjunto com o diagnóstico inicial, uma perspectiva da progressão dos alunos no decorrer da implementação da proposta BET.

Ao final, aplicamos um questionário a fim de oportunizar aos alunos uma avaliação pessoal sobre a experiência de aprendizagem vivenciada, motivando-os a apontar sugestões de melhoria.

Para avaliar a proficiência na habilidade da leitura em inglês dos alunos, definimos uma rubrica $^{8}$, conforme apresentado no Quadro 2. Os níveis de desempenho estabelecidos na rubrica avaliativa (Básico, Intermediário e Avançado) obedecem às nomenclaturas dos níveis de proficiência propostos pelo Quadro Europeu Comum de Referência para Línguas $(\mathrm{QECR})^{9} \mathrm{e}$ pelo exame Test of English as a Foreign Language (TOEFL) ${ }^{10}$. Os critérios foram inspirados no trabalho de Tumolo e Tomitch (2007), denominados originalmente de decodificação e integração, os quais foram renomeados como: decodificação de palavras e integração de ideias.

Quadro 2 - Rubrica de avaliação da proficiência na habilidade da leitura dos alunos

\begin{tabular}{|c|c|c|c|}
\hline Critérios & Básico & Intermediário & Avançado \\
\hline $\begin{array}{l}\text { Decodificação de } \\
\text { palavras }\end{array}$ & $\begin{array}{l}\text { Decodifica o } \\
\text { significado de até } \\
49 \% \text { das palavras } \\
\text { destacadas no texto. }\end{array}$ & $\begin{array}{l}\text { Decodifica o } \\
\text { significado entre } 50 \text { a } \\
70 \% \text { das palavras } \\
\text { destacadas no texto. }\end{array}$ & $\begin{array}{l}\text { Decodifica o } \\
\text { significado entre } 71 \% \text { a } \\
100 \% \text { das palavras } \\
\text { destacadas no texto. }\end{array}$ \\
\hline $\begin{array}{l}\quad \text { Integração de ideias } \\
\text { [Produção textual em } \\
\text { língua portuguesa que se } \\
\text { refere ao entendimento e } \\
\text { exposição clara das ideias } \\
\text { presentes no texto] }\end{array}$ & $\begin{array}{l}\text { Nenhuma ideia ou } \\
\text { ideias sem } \\
\text { organização na } \\
\text { construção sintática, } \\
\text { comprometendo a } \\
\text { clareza. }\end{array}$ & $\begin{array}{l}\text { Alguma(s) ideia(s) } \\
\text { do texto com pouca } \\
\text { organização na } \\
\text { construção sintática, } \\
\text { não comprometendo } \\
\text { a clareza. }\end{array}$ & $\begin{array}{l}\text { Toda(s) ideia(s) do } \\
\text { texto, com boa } \\
\text { organização na } \\
\text { construção sintática e } \\
\text { boa clareza. }\end{array}$ \\
\hline
\end{tabular}

Fonte: Elaboração Própria (2017)

\footnotetext{
${ }^{8}$ Rubrica é um conjunto coerente de critérios sobre o trabalho a ser realizado pelos alunos que inclui descrições de níveis de desempenho (BROOKHART, 2013).

${ }^{9}$ O QECR foi desenvolvido na União Europeia e se estabelece em um padrão internacional para descrever capacidades linguísticas. O quadro é geralmente aplicado para ajudar a definir os níveis de proficiência linguística. No caso desta pesquisa, utilizamos as nomenclaturas referentes aos níveis de proficiência para caracterizar o desempenho na habilidade de leitura dos alunos em inglês (CONSELHO DA EUROPA, 2001).

${ }^{10} \mathrm{O}$ TOEFL ou Teste de Inglês como uma Língua Estrangeira é um exame requerido para os alunos estrangeiros que almejam ingressar em universidades de países e tem a finalidade de avaliar o potencial individual de entender inglês em nível acadêmico (ENRIGHT et al., 2000).
} 


\section{Resultados e discussões}

A partir da avaliação feita da proposta de ensino, apresentamos os resultados, considerando três aspectos: (i) proficiência na habilidade da leitura em relação à decodificação de palavras; (ii) proficiência na habilidade da leitura em relação à integração de ideias; e, (iii) observações sobre a implementação de BET.

\section{Proficiência na habilidade da leitura em relação à decodificação de palavras}

Tomando como referência de avaliação a rubrica apresentada no Quadro 2, e levando em conta as avaliações realizadas pelos alunos na execução de BET, verificamos que para o critério decodificação de palavras, o nível de proficiência na habilidade da leitura em inglês dos alunos, foi melhorando progressivamente, conforme ilustra a Figura 3. Na avaliação inicial, a maioria dos alunos (14) estava no nível básico. Na avaliação intermediária, por sua vez, a maioria dos alunos se concentrou no nível intermediário e avançado; enquanto que na avaliação final a maioria dos alunos alcançou o nível avançado, demonstrando habilidade para descodificar o significado de mais de $71 \%$ de palavras destacadas nos textos em inglês lidos.

Figura 3 - Proficiência na habilidade da leitura dos alunos no que diz respeito à decodificação de palavras

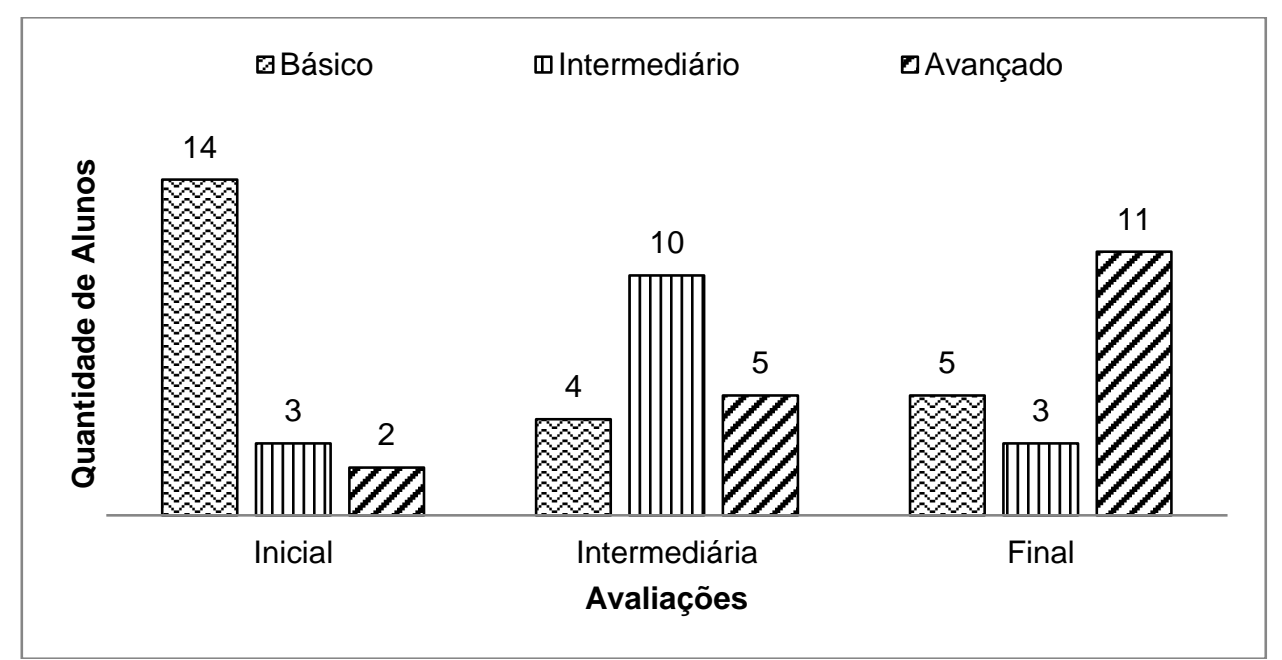

Fonte: Elaboração Própria (2017)

De modo geral, os alunos conseguiram decodificar cognatos, falsos cognatos e estrangeirismos com maior frequência, enquanto que o menor índice de decodificação foi para palavras formadas por prefixos, sufixos, marcadores do discurso e referentes pronominais. 
Sobre a decodificação de palavras, formadas por prefixos e/ou sufixos, percebemos que a dificuldade dos alunos está primeiramente em encontrar a raiz e então reconhecer o prefixo e o sufixo. Também apresentaram dificuldade em reconhecer a mudança de significado que estas desinências provocam na palavra. Embora não para os mesmos afixos, Monzón e Fadanelli (2016) também notificam dificuldades de alunos de cursos técnicos em Informática e Eletrotécnica, com a leitura de palavras com afixos e sua função no vocabulário.

Com respeito aos marcadores do discurso, os alunos revelaram mais dificuldades em decodificar conjunções e conectores que expressavam contraste e causa/consequência, itens lexicais presentes nos manuais e tutorias.

Em síntese, para o critério decodificação de palavras, quando observamos o progresso dos alunos nas avaliações intermediária e final, em relação à avaliação inicial de diagnóstico, encontramos evidências de que BET contribuiu para melhoria da proficiência na habilidade da leitura dos alunos.

\section{Proficiência na habilidade da leitura em relação à interação de ideias}

Com relação ao critério integração de ideias, os resultados para todas as avaliações desenvolvidas apontam que a proficiência na habilidade da leitura concentrou-se no nível básico, conforme demonstrado na Figura 4.

Figura 4 - Proficiência na habilidade da leitura dos alunos no que diz respeito à integração de ideias

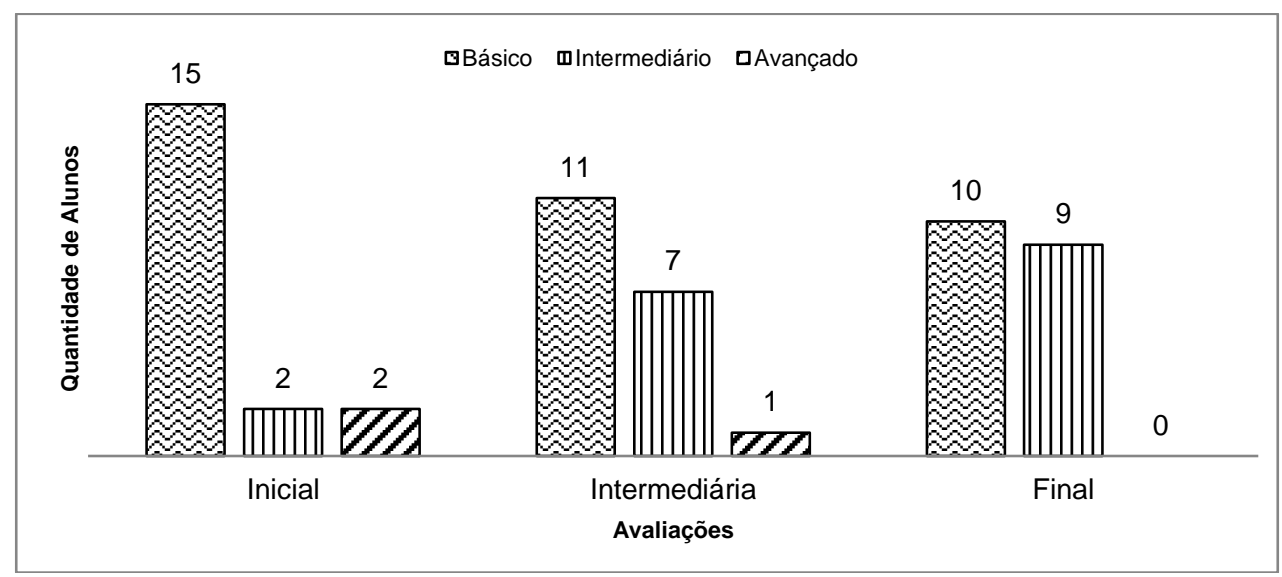

Fonte: Elaboração Própria (2017) 
Para responder as tarefas avaliativas, os alunos tinham que expressar em português o seu entendimento sobre um pequeno texto extraído de algum manual ou tutorial pertencente ao corpus. O texto produzido pelos alunos, mesmo sendo em sua língua materna, apresentava, em geral, palavras soltas, repetição dos termos em inglês ou traduções literais sem a definida organização sintática, comprometendo a expressão clara das ideias. Isto foi verificado até mesmo nos casos de alunos com experiência prévia em inglês, por meio de cursos de idiomas.

Alguns alunos demonstraram proficiência em nível intermediário e observamos que alguns desses alunos mantinham o uso de termos em inglês, tais como date recovery (Figura 5). Apesar de não estar com a grafia correta (o correto é data), esse excerto demonstra que o aluno identificou algumas ideias do texto lido, no entanto, sua resposta apresenta-se com pouca organização na construção sintática, conforme demonstramos na Figura 5.

Figura 5 - Excertos referentes ao nível intermediário na avaliação inicial.

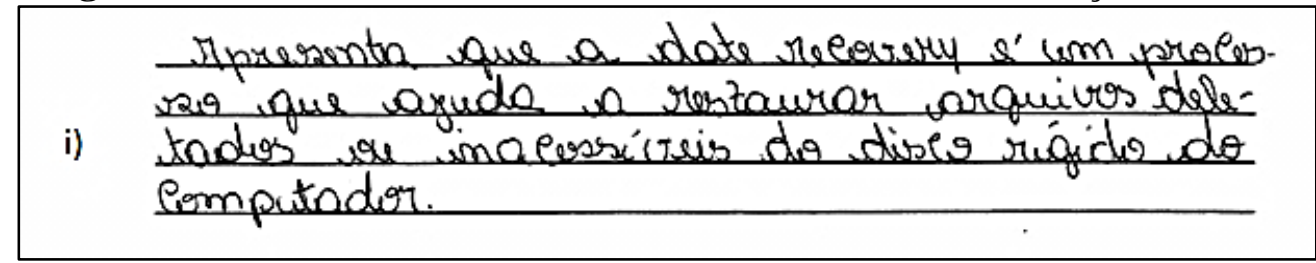

Fonte: Respostas da avaliação inicial (2017)

Em virtude do que observamos, vislumbramos que em implementações futuras, para que o desenvolvimento da habilidade de leitura para o critério integração de ideias seja mais efetivo, é necessário implementar outro modelo de ensino híbrido, diferente de rotação por estações. Acreditamos que para este caso, o modelo de laboratório rotacional seja mais adequado. Isto é, na sala de aula, o professor usaria o tempo para demonstrar exemplos de escrita sobre as ideias do texto construído pelos próprios alunos, apontando as falhas e as corrigindo em conjunto com os mesmos. Posteriormente, os alunos poderiam utilizar o laboratório para, em um formato de "oficina", praticarem a escrita de ideias do texto e também desenvolverem trabalhos em pares, no qual um aluno ora escreve, ora ler a produção de um colega, apontando dificuldades de entendimento na leitura e trabalhando conjuntamente para correção. Destacamos que a efetividade desta nova perspectiva de implementação de BET somente poderá ser avaliada em trabalhos futuros.

Com consequência direta deste trabalho, desenvolvemos dois produtos educacionais: (i) Guia Didático ${ }^{11}$ para professores de IFE sobre como implementar BET em sala de aula. Este

${ }^{11}$ Link foi omitido para preservar a identidade dos autores durante o processo de avaliação do artigo. 
guia apresenta não apenas o passo-a-passo para implementação da proposta de ensinoaprendizagem, como também disponibiliza um conjunto de recursos digitais de apoio para professores; (ii) um corpus $^{12}$ constituído de manuais e tutorias de hardwares e softwares em inglês, que pode subsidiar a docência de outros professores de inglês que atuem em Cursos Técnicos e Superiores de Informática.

\section{Observações sobre a implementação de BET}

O tempo definido para o trabalho nas estações é um aspecto que deve ser estimado com cuidado pelo professor, sobretudo, com atividades de leitura, pois os ritmos dos alunos são diferentes. Mesmo com uma avaliação positiva sobre a adequação do tempo para as atividades, cabe ressaltar que no início da implementação de BET, os alunos tinham dificuldades em concentrar sua atenção e gerenciar adequadamente o tempo para a realização das atividades, dificuldades que foram sendo minimizadas ao longo das aulas.

Outro aspecto observado diz respeito aos recursos digitais utilizados, especialmente a plataforma Duolingo, em que os alunos avaliaram como principais contribuições, o aumento de vocabulário e a melhoria na habilidade da leitura e na compreensão de frases.

Embora o modelo de sala de aula invertida pressuponha necessariamente o estudo extraclasse, o tempo de dedicação dos alunos fora de sala de aula é bastante limitado, principalmente, pelo fato de eles terem que se dedicar também a outras disciplinas. De acordo com a autoavaliação feita pelos alunos, eles relataram estudar, em média, 30minutos por semana fora de sala de aula. Isto requer de professor uma seleção minuciosa dos materiais didáticos indicados para estudos extraclasse.

Com respeito à utilização do corpus compilado para esta proposta, verificamos a importância de trabalhar com palavras de alta frequência do léxico da área técnica dos alunos, oportunizando decodificar uma quantidade e diversidade de palavras importantes para o satisfatório desempenho da habilidade de leitura de textos em inglês, respectivos a essa área de atuação.

Sobre os textos utilizados (manuais e tutoriais), os alunos foram solicitados a atribuir uma nota de 0,0 a 10,0 para a qualidade dos textos, no questionário de avaliação da proposta. Neste critério, $84,2 \%$ dos alunos atribuíram notas maiores ou iguais a sete (nota $\geq 7,0$ ). Embora

${ }^{12}$ Link foi omitido para preservar a identidade dos autores durante o processo de avaliação do artigo. 
a nota atribuída indique qualidade, os alunos sugeriram a utilização de outros tipos de textos que tenham como foco notícias sobre jogos, filmes, séries de TV e até mesmo letras de música.

Nesse aspecto, cabe destacarmos que a elaboração do corpus teve o cuidado de preservar os objetivos de aprendizagem da área específica da turma, caracterizando o propósito do ensinoaprendizagem de Inglês para Fins Específicos para o Curso Técnico de Nível em Informática. Contudo, acreditamos que nesse contexto de construção e aplicação de corpus, outras amostras podem ser criadas, como por exemplo, corpus de notícias sobre tecnologias, mantendo o foco na área técnica do aluno.

\section{Considerações finais}

Consideramos que a associação dos elementos que estabelecem a proposta de ensinoaprendizagem BET revela o estabelecimento de uma dinâmica diferenciada em sala de aula e pode potencializar a autonomia e flexibilidade dos alunos em seus estudos, sobretudo com relação às atividades de leitura e compreensão de textos em inglês.

Em síntese, o desenvolvimento e aplicação da proposta BET proporcionou mudanças significativas no ensino-aprendizagem de IFE; modificação na organização da sala de aula, por intermédio das estações, consentindo que os alunos realizassem as atividades de forma individual e também colaborativa em determinados momentos e, inclusive, compartilhassem o que aprendiam; variação na rotina, tanto para a professora, que fez a mediação dos conteúdos, como para os alunos que realizaram o estudo de maneira autônoma, dedicando-se fora da sala de aula para a realização de atividades designadas. Desta forma, acreditamos que os resultados da implementação e a avaliação de atividades desenvolvidas na proposta BET podem somar a outras pesquisas desenvolvidas nesta área.

Ressaltamos que os professores podem utilizar a proposta BET com o uso de outros recursos tecnológicos que sejam mais adequados e/ou convenientes aos seus contextos de ensino ou preferências, levando em conta, que a relevância em fornecer aos alunos um conjunto de recursos síncronos e/ou assíncronos que auxiliem o estudo presencial e extraclasse, promovendo a efetividade dos modelos de ensino híbrido previstos para a proposta BET.

Nesse sentido, sugerimos o aprofundamento do tema, voltado à geração de novos processos e produtos direcionados ao ensino-aprendizagem de IFE. Como trabalhos futuros, sugerimos a compilação de outro corpus para outros gêneros textuais, como por exemplo, o 
gênero notícias, abrangendo textos sobre tecnologia e inovação no campo da ciência, ampliando assim, o potencial de material de apoio para professores.

Indicamos, também, como desdobramento para futuras pesquisas, investigação sobre o potencial da plataforma Duolingo, no contexto da aprendizagem de IFE, inclusive, o uso dos recursos para auxiliar no desempenho da leitura.

\section{REFERÊNCIAS}

BERBER SARDINHA, T. Linguística de corpus: histórico e problemática. D.E.L.T.A., v. 16, n. 2, p. 323-367, 2000.

BERBER SARDINHA, T. Linguística de corpus. Barueri, SP: Editora Manole Ltda, 2004.

BERGMANN, J.; SAMS, A. Sala de Aula Invertida, uma Metodologia Ativa de Aprendizagem, GEN Editorial, Rio de Janeiro, 2016.

BRAUER, K. C. N. O Emprego das Estratégias de Leitura em Textos de Inglês como LE. HOLOS, v. 5, p. 165-181, 2014.

BROOKHART, S. M. How to create and use rubrics for formative assessment and grading. Alexandria, VA: ASCD, 2013.

CHRISTENSEN, C. M.; HORN, M. B.; STAKER, H. Ensino Híbrido: uma Inovação Disruptiva? Uma introdução à teoria dos híbridos. Clayton Christensen Institute, 2013.

CONSELHO DA EUROPA. Quadro europeu comum de referência para as línguas. Porto: ASA, 2001.

DUARTE, G. B. O processo de gamificação e a aprendizagem de línguas pelo viés da Complexidade. Congresso Ibero-americano de Ciência, Tecnologia, Inovação e Educação, Buenos Aires - Argentina, 2014.

ENRIGHT, M.; GRABE, W.; KODA, K.; MOSENTHAL, P. TOEFL 2000 Reading framework. Princeton, NJ: Educational Testing Service, 2000.

GONÇALVES, S. Aprender a ler e compreensão do texto: processos cognitivos e estratégias de ensino. Revista Iberoamericana de educación, v. 46, p. 135-151, 2008.

MONZÓN, A. J. B.; FADANELLI, S. B. Leitura de textos especializados anglófonos no Ensino Técnico: idiossincrasias terminológicas e pedagógicas sob a perspectiva da Linguística de Corpus. LínguaTec, v. 1, n. 1, 2016.

PORVIR. Plataforma Adaptativa: Ferramenta que propõe atividades diferentes para cada aluno, de acordo com suas necessidades. Disponível em: <http://www.porvir.org/especiais/personalizacao/?portfolio=espaco>. Acesso em: 09 jun. 2018. 
SAWAYA, M. R. Dicionário de Informática \& Internet. Nobel Editora, São Paulo, 1999.

SOUZA, P. R., ANDRADE, M. C. F. Ensino Híbrido - Modelos de Rotação por Estações de Trabalho e Sala de Aula Invertida. In: MENDONÇA, A. P. (Org.). Tendências e Inovações no Ensino. Curitiba, PR: CRV, p.27-42, 2015.

TUMOLO, C. H. S.; TOMITCH, L. M. B. Avaliando a leitura em inglês: uma reflexão sobre itens de testes. Revista Brasileira de Linguística Aplicada, v. 7, n. 2, p. 67-89, 2007.

\section{Como citar este artigo:}

SOUSA, Yna Honda de.; MENDONÇA, Andréa Pereira.; COELHO, Iandra Maria Weirich da Silva. Uma proposta de ensino-aprendizagem de inglês para fins específicos baseada no ensino híbrido. Rev. EntreLínguas, Araraquara, v. 4, n. 2, p. 165-181, jul./dez., 2018. e-ISSN: 24473529. DOI: 10.29051/rel.unesp.v4.n2.2018.11615

Submetido em: $31 / 07 / 2018$

Revisões requeridas em: 25/09/2018

Aprovação final em: 16/10/2018 